\begin{tabular}{|c|l|}
\hline Title & Synthesis and electronic property of platinum nanowire and nanoparticle in mesoporous silica template \\
\hline Author(s) & Fukuoka, A tsushi; Sakamoto, Y uzuru; Higuchi, Takanori; Ichikawa, Masaru \\
\hline Citation & $\begin{array}{l}\text { Journal of Porous Materials, 13(3), 231-235 } \\
\text { https://doi.org/10.1007/310934006-8009-2 }\end{array}$ \\
\hline Issue Date & 2006-08 \\
\hline Doc URL & http://hdl.handle.net/2115/14567 \\
\hline Rights & The original publication is available at www.springerlink.com \\
\hline Type & article (author version) \\
\hline File Information & JOPM.pdf \\
\hline
\end{tabular}

Instructions for use 


\title{
Synthesis and Electronic Property of Platinum Nanowire and Nanoparticle in Mesoporous Silica Template
}

\author{
ATSUSHI FUKUOKA, * YUZURU SAKAMOTO, TAKANORI HIGUCHI, NORIYUKI \\ SHIMOMURA AND MASARU ICHIKAWA* \\ Catalysis Research Center, Hokkaido University, Sapporo 001-0021, Japan \\ E-mail: fukuoka@cat.hokudai.ac.jp,michi@cat.hokudai.ac.jp
}

Phone: 81-11-706-9160, FAX: 81-11-706-9139

\begin{abstract}
Platinum nanowires and nanoparticles were selectively synthesized in mesoporous silicas FSM-16 and HMM-1. The nanowires are $3 \mathrm{~nm}$ in diameter and several hundred $\mathrm{nm}$ to $\mu \mathrm{m}$ in length with high crystallinity. Pt nanowires and nanoparticles can be isolated by dissolving silica matrix with HF. The Pt wires extracted from organosilica HMM-1 have a nanonecklace structure, while the wires from siliceous FSM-16 have a nanorod structure. The extracted Pt nanoparticles ( $3 \mathrm{~nm}$ in size) on HOPG show the Coulomb staircase phenomena in STM/STS analysis. The mechanism for formation of the Pt nanowires is based on the migration of Pt ions in the mesoporous channels.
\end{abstract}

Keywords: nanowire, nanoparticle, mesoporous silica, template synthesis, Coulomb staircase Abbreviation: Synthesis and Electronic Property of Platinum Nanowire

\section{Introduction}

Nanoparticles and nanowires are a class of key precursors to highly ordered, nanostructured materials in the bottom-up approach in nanotechnology [1-5]. Among various preparation techniques of nanowires and nanoparticles, the templates synthesis [6] is one of the promising methods, in which uniform void spaces of porous materials are used as a host to confine wires and particles as a guest [3,7]. Mesoporous silicas such as siliceous FSM-16 [8,9], MCM-41[10], SBA-15 [11], and organosilica HMM-1 [12] have a two dimensional (2D) hexagonal structure (p6mm symmetry) of 1D-channels less than $10 \mathrm{~nm}$ in diameter and a high surface area up to 1000 $\mathrm{m}^{2} \mathrm{~g}^{-1}$. Therefore, the mesoporous silicas provide great opportunities as a template of nanostructured materials. 
In our study of the ship-in-bottle synthesis of metal clusters in microporous zeolites [7,13], we extended this chemistry from zeolites to mesoporous silicas and found the formation of metal nanowires in the mesopores [14-24]. Here we report selective synthesis of metal nanowires and nanoparticles in FSM-16 and HMM-1. The nanostructured materials are characterized by physicochemical methods such as TEM, XRD, XAFS, STM, and gas adsorption. The electronic property of extracted Pt nanoparticles was studied by the STM/STS measurements. Formation mechanism of the nanowires is discussed in terms of migration and reduction of metal ions.

\section{Experimental}

Siliceous FSM-16 [9] and organosilica HMM-1 with bridging $-\mathrm{CH}_{2} \mathrm{CH}_{2}-$ groups [12,25] were prepared according to the literature methods (pore diameter $3 \mathrm{~nm}$ ). In typical synthetic procedures, FSM-16 was dried under vacuum (ca. $10^{-3}$ Torr, 1 Torr $=133 \mathrm{~Pa}$ ) at $623 \mathrm{~K}$ for $2 \mathrm{~h}$ and was impregnated with $\mathrm{H}_{2} \mathrm{PtCl}_{6} \cdot 6 \mathrm{H}_{2} \mathrm{O}$. The pale yellow powder, $\mathrm{H}_{2} \mathrm{PtCl}_{6} / \mathrm{FSM} \mathrm{C}$, was charged in a quartz cell and exposed to water vapor (ca. 20 Torr) for $2 \mathrm{~h}$ using vacuum line technique and then to methanol vapor (ca. 100 Torr) for $2 \mathrm{~h}$. The resulting sample was irradiated with UV light using a high-pressure mercury lamp $(100 \mathrm{~W}, 250-600 \mathrm{~nm})$ for $48 \mathrm{~h}$. After the UVirradiation, the gray powder was dried under vacuum. On the other hand, $\mathrm{H}_{2}$-reduction of $\mathrm{H}_{2} \mathrm{PtCl}_{6} / \mathrm{FSM}-16$ was performed in flowing $\mathrm{H}_{2}\left(20 \mathrm{ml} \mathrm{min}^{-1}\right)$ at $673 \mathrm{~K}$ for $2 \mathrm{~h}$ using a U-type glass reactor.

In the isolation of Pt nanowires from the mesoporous silicas, aqueous HF (ca. 46 wt \%) was diluted with ethanol to $2.5 \mathrm{wt} \%$, and to this solution was added the solid sample. After a few minutes the solution turned pale gray and black powders of Pt wires were precipitated. The unsupported Pt nanowires were filtered and washed with ethanol (Pt yield 60-70\%). In some experiments, $\left[\mathrm{N}\left(\mathrm{C}_{18} \mathrm{H}_{37}\right) \mathrm{Me}_{3}\right] \mathrm{Cl}$ or $\mathrm{PPh}_{3}$ was added to the HF solutions as a stabilizing ligand.

In the characterization of nanowires and -particles, XRD patterns were recorded on a Rigaku Miniflex using $\mathrm{Cu} \mathrm{K} \alpha$ radiation. TEM and EDX were performed with a Hitachi H-800, a JEOL JEM-2000EXII and a JEOL 2000ES with an acceleration voltage of $200 \mathrm{kV}$. XAFS spectra at the Pt $\mathrm{L}_{\text {III }}$ edge $(11562 \mathrm{eV})$ were measured at the BL-10B station in the Photon Factory of High Energy Accelerator Research Organization (KEK-PF, Tsukuba), and the data were analyzed by a REX2000 program (Rigaku). Adsorption of $\mathrm{H}_{2}$ and $\mathrm{CO}$ was performed using a Coulter Omnisorp 100CX or a Quantachrome Chembet-3000. 
For STM observation, the ethanol solution of extracted Pt wires or particles was deposited on a freshly cleaved HOPG $(8 \times 8 \mathrm{~mm})$, and the sample was dried in air. STM images were acquired at room temperature under air using a JEOL JSPM-5200 with a Pt-Ir alloy tip. Topographic images were obtained in the constant current mode with a positive bias voltage applied to the tip. For the measurements of I-V characteristics, the STM image of a nanoparticle was first taken, then the tip was fixed on the particle, and finally the feedback was switched off to detect the I-V characteristics. $1024 \mathrm{I}-\mathrm{V}$ data points were collected in a voltage sweep of $\pm 2 \mathrm{~V}$ across zero with an interval of $167 \mu \mathrm{sec}$.

\section{Results and Discussion}

Synthesis and Characterization of Pt Nanowires and Nanoparticles

Pt nanowires and nanoparticles are selectively synthesized in mesoporous silica supports FSM-16 and HMM-1 by photoreduction and thermal $\mathrm{H}_{2}$-reduction. FSM-16 was impregnated with $\mathrm{H}_{2} \mathrm{PtCl}_{6}$ ( $\mathrm{Pt} 5 \mathrm{wt} \%$ ) from an aqueous solution, and water and methanol vapors were added to the impregnated sample, $\mathrm{H}_{2} \mathrm{PtCl}_{6} / \mathrm{FSM}-16$. UV-irradiation to the sample for $48 \mathrm{~h}$ led to the formation of $\mathrm{Pt}$ nanowires. It is well known that transition metal colloids are formed by thermal or radiochemical reactions in water/alcohol solutions [26,27]. We applied the colloid synthesis in solutions to the reaction in solid mesoporous supports. In this method, adsorbed water and methanol are solvents in the nanospace, and methanol also works as a reducing agent under UVirradiation.

In the TEM images of Pt/FSM-16 (Figure 1a,b), Pt wires and particles are clearly seen as dark stripes and dots. The Pt nanowires are $3 \mathrm{~nm}$ in diameter in accord with the pore diameter of FSM$16(3 \mathrm{~nm})$, and the length ranges from ten to several hundred $\mathrm{nm}$ reflecting the 1D channel structure. This result indicates the formation of nanowires inside the channels. Actually, almost no wire or particle is observed on the external surface of FSM-16. In contrast, Pt nanoparticles prepared by $\mathrm{H}_{2}$-reduction of $\mathrm{H}_{2} \mathrm{PtCl}_{6} / \mathrm{FSM}-16$ at $673 \mathrm{~K}$ have a diameter of $3 \mathrm{~nm}$. Similar results were obtained using MCM-41, SBA-15, and HMM-1 as supports. We have so far synthesized nanowires of Rh, Pd, Pt, Au and bimetallic Pt-Rh, Pt-Pd by the photoreduction method [14-24]. In the HRTEM images of the wires, lattice fringes of crystal planes were clearly observed, and the EDX analysis showed that the bimetallic Pt-Rh and Pt-Pd nanowires have the same compositions as charged $\mathrm{Pt} / \mathrm{Rh}$ (or $\mathrm{Pd}$ ) ratios. Hence, the nanowires have high crystallinity and 
the bimetallic wires are alloy. The XRD patterns at low $2 \theta$ angle show no significant change before and after incorporation of metal, indicating that the 2D-hexagonal pore structure remained unchanged (Figure 2). In the high $2 \theta$ region, typical diffraction peaks due to $f c c$ crystalline were observed.

Figure 1 and Figure 2

The uptake of $\mathrm{CO}(\mathrm{CO} / \mathrm{Pt})$ is 0.07 for Pt nanowire/FSM-16 and 0.24 for Pt nanoparticle/FSM16, respectively, which reasonably shows that the surface area of Pt nanowire is smaller than that of Pt nanoparticle. The dispersion data also imply that the internal mesopores are not completely plugged with nanowires, because the uptake of $\mathrm{CO}$ would be equal to the atomic ratio of basal face to bulk (0.005) with tight filling of pores with nanowires. By considering that the atomic ratio of whole surface to bulk is 0.35 , the CO uptake data suggest that $20 \%$ of the side surface is exposed to the gas phase. This enables the side surface to work as adsorption sites for small molecules such as $\mathrm{CO}, \mathrm{O}_{2}$, and $\mathrm{H}_{2}$.

Extraction of nanowires from mesoporous supports is important in the application of nanowires as a building block. In addition, detailed characterization of nanowires is possible by the extraction. The metal nanowires and nanoparticles are successfully separated by dissolving silica matrix with diluted HF. Pt nanowires were isolated as a black solid in $60-70 \%$ yield, and the EDX analysis confirmed the removal of Si. The unsupported Pt nanowires were entangled (Figure 1c), but each wire keeps their original structure without fusion. Thus the length of nanowires can be accurately measured, and the longest one was $25 \mu \mathrm{m}$ (aspect ratio 8300). The extracted Pt nanowires were stable as a solid at $278 \mathrm{~K}$, but in ethanol suspension they aggregated to form big particles (ca. $20 \mathrm{~nm}$ ) in 2 days at $278 \mathrm{~K}$. Addition of $\left[\mathrm{N}\left(\mathrm{C}_{18} \mathrm{H}_{37}\right) \mathrm{Me}_{3}\right] \mathrm{Cl}$ and $\mathrm{PPh}_{3}$ was effective to stabilize nanowires in solutions.

Ligand-free Pt nanowires and nanoparticles were deposited on HOPG, and the surface morphology was studied by STM (Figure 3). It is notable that the Pt wire extracted from FSM-16 has a rod-like structure with smooth surface, but the Pt wire from HMM-1 has a necklace-like structure. We propose that the Pt-support interaction for HMM-1 is weaker than that for FSM-16 due to the hydrophobicity of organic groups. The hydrophobic interaction at the interface results in the increase in surface energy of Pt metal to give the nanonecklace structure.

Figure 3 
The Coulomb blockade phenomena and staircase structures have been observed in the STM/STS study of extracted Pt nanoparticles. A typical I-V curve for Pt nanoparticle (diameter 3 $\mathrm{nm}$, Figure 3c) on HOPG is shown in Figure 4. Steps in the curves are clearly seen in the negative voltage range, and the $\mathrm{dI} / \mathrm{dV}$ curve indicates the appearance of the Coulomb staircase. We suggest that the Coulomb staircase structure is associated with the single electron tunneling from the Pt nanoparticle through the tip. $\Delta \mathrm{V}$ and $\Delta \mathrm{I}$ in the $\mathrm{I}-\mathrm{V}$ curve were $63 \mathrm{mV}$ and $2.15 \mathrm{nA}$, and the charging energy is estimated to be $32 \mathrm{meV}$, which is higher than the thermal energy at room temperature $(26 \mathrm{meV})$.

Figure 4

\section{Mechanism for Formation of Pt Nanowires}

Mechanism for formation of Pt nanowires has been studied by changing UV-irradiation time in the photoreduction of $\mathrm{H}_{2} \mathrm{PtCl}_{6} / \mathrm{HMM}-1$. In the TEM images, small Pt particles (up to $3 \mathrm{~nm}$ ) are seen after $4 \mathrm{~h}$. Pt nanoparticles and short nanowires (mean length $10 \mathrm{~nm}$ ) are observed after $8 \mathrm{~h}$. Pt wires are clearly observed after irradiation of $12 \mathrm{~h}$, and the mean length is $90 \mathrm{~nm}$. The wires grow longer by further irradiation for 24 and $48 \mathrm{~h}$; the mean lengths are 120 and $220 \mathrm{~nm}$, respectively. The XRD profiles of the Pt/HMM-1 samples also show the growth process of $\mathrm{Pt}$ crystalline with increased irradiation time (Figure 5a). The Pt/HMM-1 samples with various UVirradiation time were also characterized by XAFS. Figure $5 \mathrm{~b}$ exhibits Fourier transforms of $\mathrm{k}^{3}-$ weighted EXAFS functions $\chi(\mathrm{k})$ of Pt/HMM-1 and Pt foil. In the curve-fitting analysis, the peaks were ascribed to Pt-Cl and Pt-Pt. The contribution of Pt-O was not observed in the curve-fitting analysis. The coordination number $(\mathrm{CN})$ of $\mathrm{Pt}-\mathrm{Cl}$ declines from 5.9 to $0.4 \mathrm{in} 12 \mathrm{~h}$, indicating that the reduction of $\mathrm{H}_{2} \mathrm{PtCl}_{6}$ is almost completed in $12 \mathrm{~h}$. The $\mathrm{CN}$ of $\mathrm{Pt}-\mathrm{Cl}$ is further decreased to ca. 0 in $48 \mathrm{~h}$. On the other hand, the $\mathrm{CN}$ of Pt-Pt is increased from 0 to $8.2 \mathrm{in} 12 \mathrm{~h}$, and then slightly increased to 9.1 in $48 \mathrm{~h}$.

\section{Figure 5}

From above experimental results, we propose the mechanism for formation of Pt nanowires as shown in Figure 6. First, tiny Pt nanoparticles are formed in the mesoporous channels by the photoreduction of $\mathrm{H}_{2} \mathrm{PtCl}_{6}$. It is suggested that organic radicals such as $\cdot \mathrm{CH}_{2} \mathrm{OH}$ are produced from adsorbed methanol under UV-irradiation, and the radicals reduce $\mathrm{Pt}(\mathrm{IV})$ ions to $\mathrm{Pt}(0)$. In fact, no reaction occurred in the absence of methanol. When only methanol was adsorbed on 
$\mathrm{H}_{2} \mathrm{PtCl}_{6} / \mathrm{HMM}-1$, reduction took place under irradiation, but big Pt particles were formed as a major product on the external surface of HMM-1. Therefore, water is necessary as a co-solvent for the formation of nanowires inside the channels. The Pt ions are soluble in the water/methanol phase and can migrate in the channels. Then the Pt ions are catalytically reduced on the surface of Pt nanoparticles to grow nanowires. Hence, the key to synthesizing Pt nanowires is to promote migration of $\mathrm{Pt}$ ion in the $1 \mathrm{D}$ channel. Under our $\mathrm{H}_{2}$-reduction conditions, migration of $\mathrm{Pt}$ ion is difficult and growth of Pt nanoparticle to nanowire does not occur. If small amount of water remains after impregnation of $\mathrm{Pt}$ ions, Pt nanowires may be formed by facilitating the migration of Pt ions.

Figure 6

\section{Conclusion}

It is demonstrated in this work that metal nanowires and nanoparticles are selectively synthesized by photo- and thermal $\mathrm{H}_{2}$-reduction in FSM-16 and HMM-1 as templates. The diameter of $\mathrm{Pt}$ nanowires is $3 \mathrm{~nm}$ and the aspect ratio is as high as ca. 8000, and the nanowires have high crystallinity. The selective formation of nanowires and nanoparticles by photo- and $\mathrm{H}_{2}$-reduction is determined by the relative rate of migration and reduction of $\mathrm{Pt}$ ions. The metal nanowires and nanoparticles are successfully isolated by dissolving silica with HF-treatment. The morphology of Pt nanowires is influenced by the hydrophobicity and hydrophilicity of internal surface of mesoporous channels; the Pt wire is a nanorod in siliceous FSM-16 but a nanonecklace in organosilica HMM-1. In the STM/STS study of Pt nanoparticles, the Coulomb blockade phenomena and staircase structures are observed, which is associated with the single electron tunneling from the Pt nanoparticle through the tip.

\section{Acknowledgments}

We thank Dr. S. Inagaki for generous gift of FSM-16. This work was financially supported by a Grant-in-Aid for Scientific Research from the Ministry of Education, Science, Sports and Culture, Japan and by CREST, Japan Science and Technology Agency.

\section{References}

1. A. P. Alivisatos, Science 271, 933 (1996). 
2. J. Hu, T. W. Odom, and C. M. Lieber, Acc. Chem. Res. 32, 435 (1999).

3. A. Fukuoka and M. Ichikawa, in Morphology Control of Materials and Nanoparticles. Advanced Materials Processing and Characterization, edited by Y. Waseda and A. Muramatsu (Springer-Verlag, Heidelberg, 2003), p.201.

4. M. A. El-Sayed, Acc. Chem. Res. 34, 257 (2001).

5. J. S. Bradley, in Clusters and Colloids, edited by G. Schmid (VCH, Weinheim, 1994), p. 459.

6. C. A. Foss, G. L. Hornyak, J. A. Stockert, and C. R. Martin, J. Phys. Chem. 96, 7497 (1992).

7. M. Ichikawa, in Metal Clusters in Chemistry, edited by P. Braunstein, L. A. Oro and P. R. Raithby (Wiley-VCH, Weinheim, 1999), vol. 3, p. 1273.

8. T. Yanagisawa, T. Shimizu, K. Kuroda, and C. Kato, Bull. Chem. Soc. Jpn. 63, 988 (1990).

9. S. Inagaki, Y. Fukushima, and Kuroda, Chem. Commun. 680 (1993).

10. C. T. Kresge, M. E. Leonowicz, W. J. Roth, J. C. Vartuli, and J. S. Beck, Nature 359, 710 (1992).

11. D. Zhao, J. Feng, Q. Huo, N. Melosh, G. H. Fredrickson, B. F. Chmelka, and G. D. Stucky, Science 279, 548 (1998).

12. S. Inagaki, S. Guan, Y. Fukushima, T. Ohsuna, and O. Terasaki, J. Am. Chem. Soc. 121, $9611(1999)$.

13. M. Ichikawa, Adv. Catal. 38, 283 (1992).

14. M. Sasaki, M. Osada, N. Sugimoto, S. Inagaki, Y. Fukushima, A. Fukuoka, and M. Ichikawa, Microporous Mesoporous Mater. 21, 597 (1998).

15. M. Sasaki, M. Osada, N. Higashimoto, T. Yamamoto, A. Fukuoka, and M. Ichikawa, J. Mol. Catal. A 141, 223 (1999).

16. A. Fukuoka, N. Higashimoto, Y. Sakamoto, M. Sasaki, N. Sugimoto, S. Inagaki, Y.

Fukushima, and M. Ichikawa, Catal. Today 66, 23 (2001).

17. A. Fukuoka, N. Higashimoto, Y. Sakamoto, S. Inagaki, Y. Fukushima, and M. Ichikawa, Microporous Mesoporous Mater. 48, 171 (2001).

18. A. Fukuoka, Y. Sakamoto, S. Guan, S. Inagaki, N. Sugimoto, Y. Fukushima, K. Hirahara, S. Iijima, and M. Ichikawa, J. Am. Chem. Soc. 123, 3373 (2001).

19. A. Fukuoka, N. Higashimoto, Y. Sakamoto, S. Inagaki, Y. Fukushima, and M. Ichikawa, Topics in Catal. 18, 73 (2002).

20. A. Fukuoka, H. Araki, Y. Sakamoto, N. Sugimoto, H. Tsukada, Y. Kumai, Y. Akimoto, and 
M. Ichikawa, Nano Lett. 2, 793 (2002).

21. H. Araki, A. Fukuoka, Y. Sakamoto, S. Inagaki, N. Sugimoto, Y. Fukushima, and M. Ichikawa, J. Mol. Catal. A 199, 95 (2003).

22. A. Fukuoka, H. Araki, Y. Sakamoto, S. Inagaki, Y. Fukushima, and M. Ichikawa, Inorg. Chim. Acta 350, 371 (2003).

23. Y. Sakamoto, A. Fukuoka, T. Higuchi, N. Shimomura, S. Inagaki, and M. Ichikawa, J. Phys. Chem. B 108, 853 (2004).

24. A. Fukuoka, H. Araki, J. Kimura, Y. Sakamoto, T. Higuchi, N. Sugimoto, S. Inagaki and M. Ichikawa, J. Mater. Chem. 14, 752 (2004).

25. S. Guan, S. Inagaki, T. Ohsuna, and O. Terasaki, J. Am. Chem. Soc. 122, 5660 (2000).

26. H. Hirai, Y. Nakao, and N. Toshima, J. Macromol.. Sci., Chem. A12, 1117 (1978).

27. M. Michaelis and A. Henglein, J. Phys. Chem. 96, 4719 (1992). 


\section{Figures}

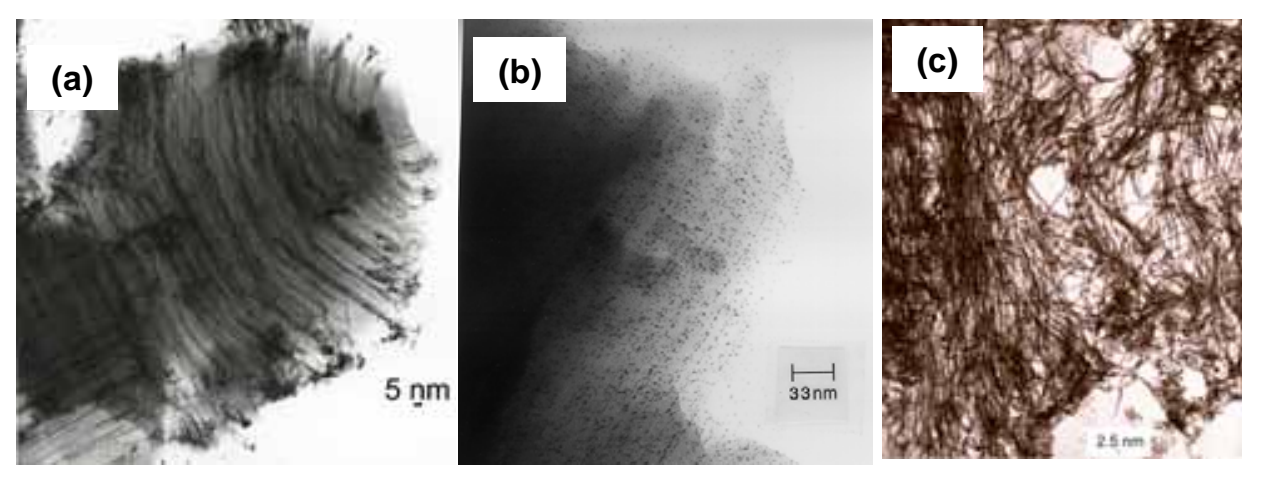

Figure 1. TEM images of (a) Pt nanowire/FSM-16 by photoreduction, (b) Pt nanoparticle/FSM16 by $\mathrm{H}_{2}$-reduction, and (c) Pt nanowires extracted from HMM-1.

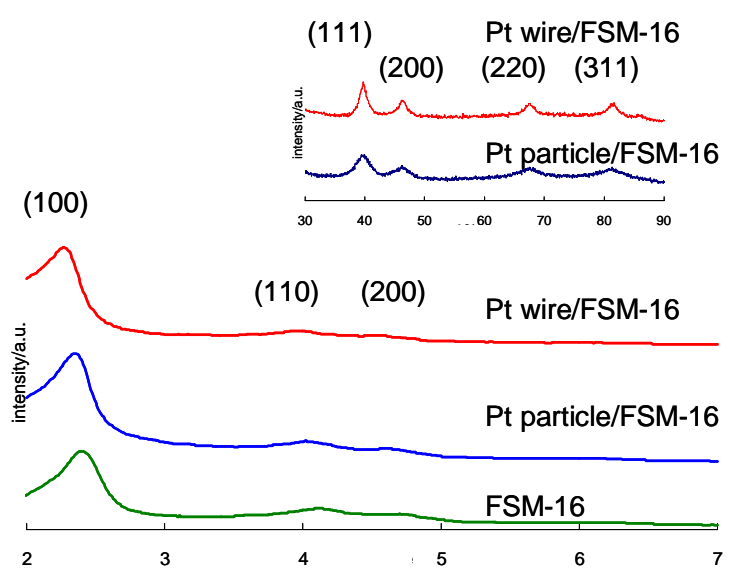

Figure 2. XRD patterns of FSM-16, Pt nanowire/FSM-16, and Pt nanoparticle/FSM-16 at low and high $2 \theta$ angle. 

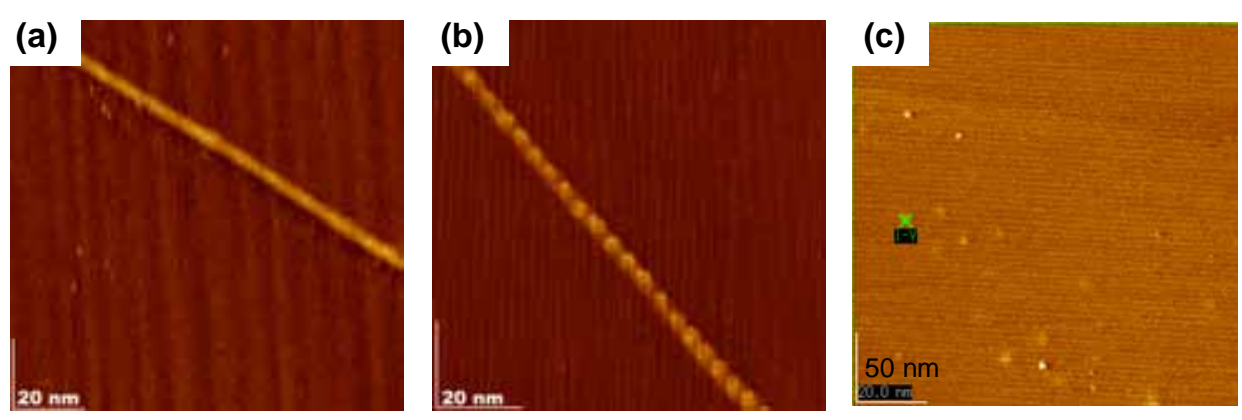

Figure 3. STM images of Pt nanowires extracted from (a) FSM-16, (b) HMM-1 and (c) Pt nanoparticles from HMM-1.
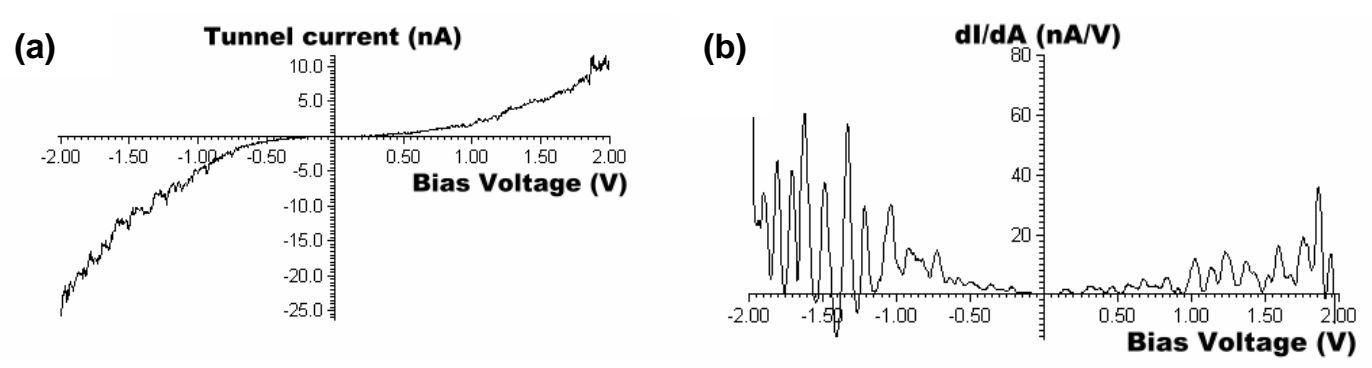

Figure 4. (a) I-V curve for Pt nanoparticle (3 nm) extracted from HMM-1. Observed in air at room temperature. (b) dI/dV curve of (a). 
(a)

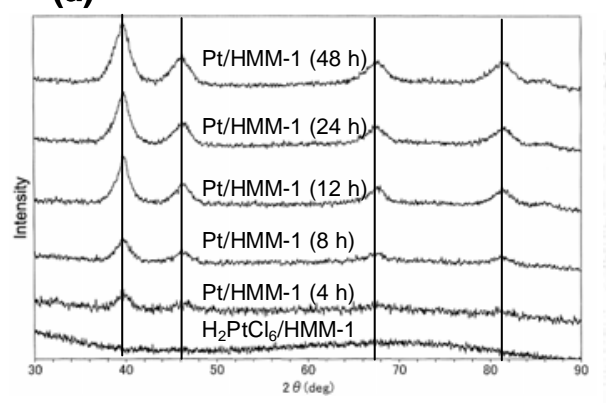

(b)

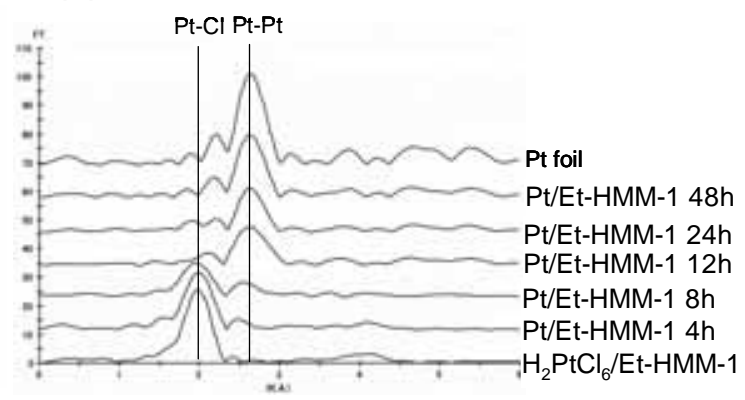

Figure 5. XRD patterns and XAFS Fourier transforms for $\mathrm{H}_{2} \mathrm{PtCl}_{6} / \mathrm{HMM}-1$ after UV-irradiation for $0-48 \mathrm{~h}$.
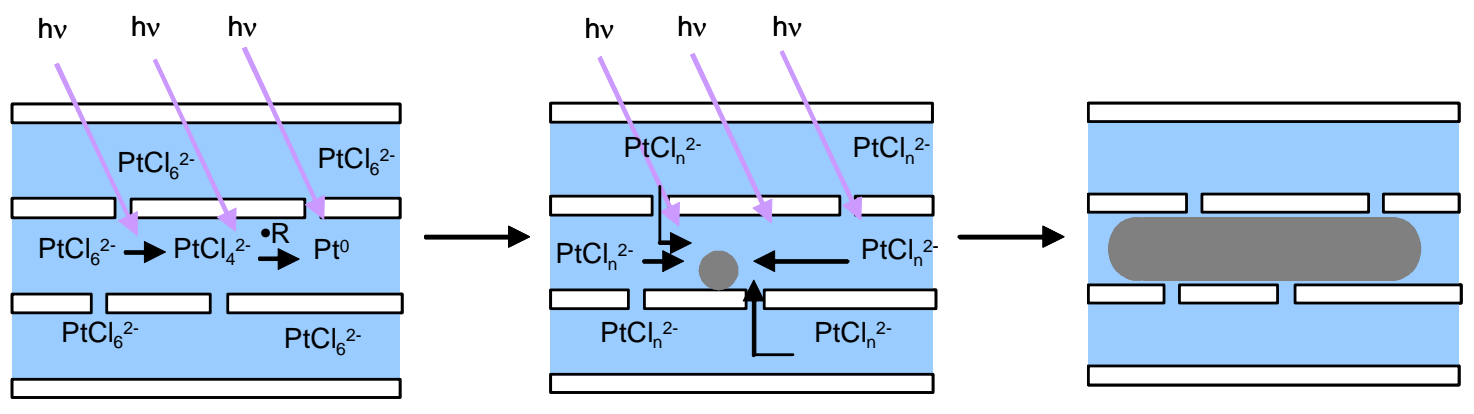

Figure 6. Proposed mechanism for formation of $\mathrm{Pt}$ nanowires in mesoporous silica. 


\section{Keywords}

\section{nanowire}

nanoparticle

mesoporous silica

template synthesis

Coulomb staircase 


\section{Contact Author}

Atsushi Fukuoka

Catalysis Research Center

Hokkaido University

Sapporo 001-0021

Japan

Phone: 81-11-706-9160

FAX: 81-11-706-9139

E-mail: fukuoka@cat.hokudai.ac.jp 